Chirurgia (2019) 114: 769-778

No. 6, November - December

Copyright $\odot$ Celsius

http://dx.doi.org/10.21614/chirurgia.114.6.769

\title{
Laparoscopic Gastric Plication vs Laparoscopic Sleeve Gastrectomy - A Single Center, Prospective and Case-Control Study
}

\author{
Radu Mircea Neagoe', Daniel Timofte' ${ }^{2}$ Mircea Mureșan', Septimiu Voidăzan³ ${ }^{3}$ Daniela Sala', Mihnea Bogdan Borz', \\ Paul Cristian Borz ${ }^{4}$, Bogdan Ciuntu ${ }^{5}$, Gheorghe G. Balan ${ }^{6}$, Oliviu Cristian Borz'
}

'University of Medicine, Pharmacy, Science and Technology of Târgu Mureș, Surgery Clinic No. 2, Tîrgu Mureș, Romania ${ }^{2}$ University of Medicine and Pharmacy Gr.T. Popa, Surgery Clinic No. 3, Iași, Romania

3University of Medicine, Pharmacy, Science and Technology of Târgu Mureș, Epidemiology Department, Tîrgu Mureș, Romania ${ }^{4}$ University of Medicine, Pharmacy, Science and Technology of Târgu Mureș, Tîrgu Mureș, Romania

${ }^{5}$ Grigore T. Popa University of Medicine and Pharmacy, Iași, Romania

${ }^{6}$ Grigore T. Popa University of Medicine and Pharmacy, Iași, Romania

Corresponding author:

Daniel Timofte, MD, PhD

Associate Professor in General Surgery

Medical Director "St. Spiridon"

Emergency Clinical Hospital

Consultant in General Surgery

Advanced Laparoscopic and Bariatric

Surgery, Department of General Surgery

University of Medicine "Gr.T.Popa"

"Sf. Spiridon" University Hospital,

700111, lasi, Romania

E-mail: dantimofte@yahoo.com

Abbreviations:

LGB - laparoscopic gastric banding;

LSG - laparoscopic sleeve gastrectomy;

LGP - laparoscopic gastric plication;

BMI - body mass index;

LMWH - low molecular weight heparin.
Received: 17.11.2019

Accepted: 19.12.2019

\section{Rezumat}

Plicatura gastrică laparoscopică vs rezectie gastrică longitudinală laparoscopică - un singur centru, studiu prospectiv și de control de caz

Istoric şi obiective: Plicatura gastrică laparoscopică (LGP) este o procedură bariatrică restrictivă, încă în curs de investigare, considerată a fi o alternativă la rezecția gastrică longitudinală laparoscopică (LSG). Scopul prezentului studiu a fost compararea rezultatelor LGP cu rezultatele LSG.

Material şi Metodă: Studiul a fost realizat pe un număr de 100 de pacienți, dintre care la un număr de 50 de pacienți s-a practicat LGP şi alți 50 de pacienți LSG. Pentru a analiza eficiența ambelor proceduri pierderea în greutate totală (\% TWL), modificarea indicelui de masă corporală $(\Delta M M I)$ şi procentul de pierdere în greutate în exces (\% EWL) au fost măsurate şi calculate pentru patru termene distincte: 6 luni, 12 luni, 24 luni şi 36 de luni de la procedură. Comorbiditățile au fost evaluate pe baza investigațiilor clinice şi de laborator.

Rezultate: Începând de la 6 luni după operație, reducerea greutății a fost semnificativă statistic în favoarea grupului LSG, cu cele mai mari diferențe constatate după doi şi trei ani postoperator $(p=0,0001)$. Nu au fost găsite diferențe între cele două proceduri în ceea ce priveşte conformitatea sau ameliorarea principalelor comorbidități. 
Concluzii: În comparație cu LSG, LGP are rezultate similare în ceea ce priveşte durata spitalizării, complicații majore şi îmbunătățirea comorbidităților principale. S-a constatat că procedura LSG este superioară în ceea ce priveşte reducerea greutătii pe termen mediu sau lung. LGP este o tehnică care poate oferi rezultate mai bune la pacienții obezi cu un IMC mai mic $\left(\mathrm{sub} 40 \mathrm{~kg} / \mathrm{m}^{2}\right)$.

Cuvinte cheie: plicatura gastrică laparoscopică, rezecția gastrică longitudinală laparoscopică, chirurgie bariatrică, indicele de masa corporală, obezitate, pierdere în greutate

\begin{abstract}
Background and objectives: The laparoscopic gastric plication (LGP) is a restrictive bariatric procedure, still under investigation, considered to be an alternative to laparoscopic sleeve gastrectomy (LSG). The aim of the present study was to compare the outcome of LGP with the results of LSG. Materials and Methods: The study was conducted on a total of 100 patients, from which 50 patients underwent LGP and other 50 patients had the LSG operation. To analyze the effectiveness of both procedures total weight loss (\%TWL), change in body mass index $(\triangle \mathrm{BMI})$ and percentage of excess weight loss (\%EWL) were measured and calculated for four distinct timelines: 6 months, 12 months, 24 months and 36 months after the procedure. Comorbidities were evaluated based on clinical and laboratory investigation.

Results: Starting from 6 months after surgery, weight reduction was statistically significant in favor of the LSG group, with the highest differences found after two and three years postoperatively $(p=0.0001)$. No differences were found between the two procedures in terms of compliance or improvement of the main comorbidities.

Conclusions: As compared to LSG, LGP has similar outcomes in terms of the length of hospitalization, major complications and improvement of the main comorbidities. LSG procedure was found to be superior in terms of medium- to long-term weight reduction. LGP is a technique that may provide better results in obese patients with a lower BMI (less than $40 \mathrm{~kg} / \mathrm{m}^{2}$ ).
\end{abstract}

Key words: laparoscopic gastric plication, laparoscopic gastric sleeve, bariatric surgery, body mass index, obesity, weight loss

\section{Introduction}

With around 500 million people affected worldwide, obesity has become a real epidemic worldwide in recent years (1). Furthermore, forecasts are less than optimistic for the forthcoming decades, with $38 \%$ of the adult population being expected to be overweight and $20 \%$ obese (2). Under such circumstances, interest in treating this condition, including through surgical methods, is justified. The development of minimally invasive surgery in the last few decades has also improved the outcomes of bariatric surgery. Various malabsorptive, restrictive or mixed techniques have emerged over time, but to date there is no ideal technique that suits all bariatric patients. Laparoscopic gastric banding (LGB) and the laparoscopic sleeve gastrectomy (LSG), remain the most used techniques, with the latter showing a clear tendency of becoming the favorite of most surgeons (3). In recent years, there has been much discussion about another restrictive technique, laparoscopic gastric plication (LGP). This surgical procedure appears to be a viable alternative to the two already established techniques. The main advantage of this procedure is the lack of resection and stapling line and, thus, a 
decrease risk of a fistula. Other advantages refer to the absence of an implanted foreign body, together with the reversibility of the procedure (4). LGP has also gained ground in the Balkan area where, in addition to the advantages mentioned above, it has economic implications, with this intervention being significantly cheaper than other bariatric operations.

The main purpose of the present study was to provide a comparative analysis of two groups of bariatric patients subjected to LGP or LSG procedure performed by two surgeons with similar experience (each with more than 150 cases performed before starting the study) from an emerging bariatric center in the $\mathrm{Tg}$ Mures. In addition, our goal was to compare the effectiveness of LGP versus the current standard restrictive technique, i.e. LSG, and to identify the niche of patients who would benefit the most from this distinct technique.

\section{Material and Method}

\section{Study Design}

All the bariatric operations performed in the Second Department of Surgery, University of Medicine and Pharmacy of Targu-Mures, Romania, between October 2010 and March 2018, were introduced into a prospective database. Out of these, 50 consecutive LGP cases were selected and matched with 50 LSG cases performed over the same time period. The interventions were performed by two surgeons, one performing the LSG, and the other having a particular interest in LGP. Standard inclusion criteria were based on the National Institute of Health 1991 bariatric surgery guidelines and the recommendation of the Romanian Surgical Society (5). Exclusion criteria were applied to patients undergoing other types of bariatric surgery and those who were followed for less than six months. All patients received preoperative psychological counseling, were informed about the type of intervention and its risks, and provided signed consent. This study was approved by the Hospital Ethics Committee.
Our database included demographic characteristics, preoperative anthropomorphic data (maximum weight and maximum BMI measured during the qualification for bariatric surgery), American Society of Anesthesiologists (ASA) physical status class and obesity-related comorbidities (diabetes mellitus, arterial hypertension, dyslipidemia, and respiratory disorders). We also noted preoperative variables and postoperative complications, defined as adverse events occurred within 30 days after the surgery and presented according to Clavien-Dindo classification. Postoperative hemorrhage was defined as the need of reoperation or postoperative transfusions. The gastric leak was diagnosed clinically and confirmed radiologically. National indications for bariatric surgery followed in this study were: a body mass index (BMI) higher than $40 \mathrm{~kg} / \mathrm{m}^{2}$ or a BMI higher than $35 \mathrm{~kg} / \mathrm{m}^{2}$ in combination with high-risk comorbid conditions, such as sleep apnea, pickwickian syndrome, diabetes mellitus, or degenerative joint disease. Also, this was considered as a last therapeutic resort if dieting, exercise, psychotherapy, and drug treatments failed.

The outcomes of bariatric surgery were evaluated 6 months after the interventions and then during the follow-up program at 12 , 24 and 36 months. The following variables were measured: total weight loss (\%TWL), change in body mass index $(\triangle \mathrm{BMI})$ and percentage of excess weight loss (\%EWL). These parameters were calculated using patients' maximal weight and/or the BMI measured preoperatively. In order to determine the $\%$ EWL, we calculated the ideal body weight as equivalent to a BMI of $25 \mathrm{~kg} / \mathrm{m}^{2}$. Satisfactory weight loss after surgery was defined by a \%EWL greater than $50 \%$.

\section{Preoperative Work-up and Surgical Procedures}

Preoperative investigations included gastroscopy, abdominal ultrasonography and evaluation of obstructive sleep apnea syndrome. Furthermore, blood glucose, triglycerides, cholesterol, hepatic enzymes were deter- 
mined, and blood pressure was measured to show metabolic diseases associated with obesity. All patients underwent preoperative fasting; thromboprophylaxis included preoperative administration of low molecular weight heparin (LMWH), along with other well-known measures (e.g., antithrombotic socks and a sequential compression device).

The LSG procedure was performed under general anesthesia, following a procedure we have described in our previous work $(6,7)$.

Regarding the LGP procedure, five trocars are needed; dissection starts approximately 5 $\mathrm{cm}$ from the pylorus further liberating the greater curvature toward the angle of His, completely dissecting the left crus of the diaphragm. Unlike sleeve gastrectomy, a safety margin must be kept along the greater curvature, in order to avoid lesions of the gastric wall. After dissection of the greater curvature, a $34 \mathrm{Fr}$ probe leaning the small curvature is used for calibration of the gastric pouch; it is very important to pass the probe into the duodenum to avoid subsequent gastric outlet obstruction. The plication begins at $2 \mathrm{~cm}$ from the angle of His and ends at $5 \mathrm{~cm}$ from the pylorus. The first layer consists of a continuous suture using 2.0 absorbable threads; the bites are only seromuscular, while the distance between two bites is $2 \mathrm{~cm}$. By using devices such as the Endostitch, our feeling is that the time taken to perform this operative step is reduced. For the second row of the plication, 2.0 non-absorbable threads are used in a running suture. At the end of the surgery, after removal of the probe, a gastric pouch is created with an even and regular shape.

\section{Postoperative Care and Follow-up}

Our patients were generally attended on the ward immediately after the surgery; any complications occurring within the first 30 days postoperatively were noted and considered to be immediate complications. A liquid diet was started on the second postoperative day, regardless of the type of surgery, and continued for two weeks after surgery. For the next 15 days, patients received a diet of blended food. Anticoagulants were prescribed for four weeks to prevent venous thrombosis and the proton pump inhibitor was also prescribed for the next one to three months.

All patients operated on, regardless of technique, were followed prospectively at three months in the first year and biannually thereafter; information was also collected by email, written correspondence or by phone. Each patient filled out a questionnaire and late complications were tracked for both types of intervention. Furthermore, the weight loss procedure was noted and discontinuation or dose reduction for specific medication was interpreted as a remission or improvement of the main comorbidities, respectively.

\section{Evaluation of the Outcomes}

To measure the effectiveness of both procedures we calculated total weight loss (\%TWL), change in body mass index $(\triangle \mathrm{BMI})$ and percentage of excess weight loss (\%EWL). Comorbidities were evaluated based on clinical and laboratory investigation and changes in pharmacological therapy (e.g., reduction of doses and/or cessation of therapy).

\section{Statistical Analysis}

All statistical calculations were performed using Graph Pad Software, San Diego, California, USA. The normal distribution for a continuous variable was tested using the KolmogorovSmirnov test. These were characterized as mean and standard deviation (SD) for variables with a normal distribution, or as median and range for variables with an abnormal distribution, respectively. Adequate statistical tests were chosen according to data distribution. Differences in mean age between genders were determined by the Student's t-test. Differences between comparative preoperative and postoperative variable values (three months and six years, respectively) were determined by an ANOVA test (associated with the Bonferroni multiple comparison test). The correlation between quantitative variables was assessed 
using a Pearson correlation, when appropriate. Statistical significance was set at $\mathrm{p}<0.05$.

\section{Results}

A total of 100 patients with a mean age of 39.3 years were included in this study. The LGP group included 50 consecutive patients, most of whom were women $(n=45,90 \%)$, with a mean age of $38.2 \pm 10.2$ years; this was matched to a group of 50 LSG patients operated on in the same period of time, also comprising mostly women $(n=46,92 \%)$, with a mean age of 40.4 \pm 9.7. Table 1 lists the main demographic, anthropomorphic, clinical, and operative characteristics of the two groups.

The two groups were similar in demographic terms; in terms of anthropomorphic characteristics, we noted statistical differences: the LSG group included patients with an initial weight and BMI higher than the LGP group $(p=0.0001)$. The LGP group included several cases with a BMI between 30 and $35 \mathrm{~kg} / \mathrm{m}^{2}$, operated on after weight-loss and having obesity-related comorbidities and therefore considered fit for a bariatric procedure. All cases were completed laparoscopically with no conversion. The operative time was similar between the studied groups. Regarding the LSG group, the number of cartridges used ranged from five to seven and oversewing was used in 31 patients $(62 \%)$; it was noticed that in the patients with oversewing, the operative time was prolonged considerably. There were no significant differences between groups regarding the associated comorbidities, although in the LSG group the number of patients with arterial hypertension $(\mathrm{AH})$, obstructive sleep apnea syndrome (OSAS) and diabetes was higher (Table 1). Hospital stay was longer for the LGP group, with a median of 5.1 days, without statistical difference between groups, but with more patients in LGP group having postoperative nausea and vomiting, which required conservative treatment and maintenance of aspiration.

Mortality in both groups was nil. There were two cases of postoperative hemorrhage in

Table 1. Demographic, anthropomorphic, clinical, and operative data. BMI=body mass index, EBW=excess body weight, $\mathrm{OSAS}=$ obstructive sleep apnea syndrome, $\mathrm{HH}=$ hiatal hernia, $\mathrm{ASA}=$ American Society of Anesthesia, pts= patients

\begin{tabular}{|c|c|c|c|}
\hline Characteristics & LSG (50 pts) & LGP (50 pts) & $P$ value \\
\hline Age(years) mean $\pm S D$ & $40.4 \pm 9.7$ & $38.2 \pm 10.2$ & $>0.5$ \\
\hline $\operatorname{Sex}(F / M), n(\%)$ & $46 / 4(92 / 8 \%)$ & $45 / 5(90 / 10 \%)$ & $>0.5$ \\
\hline $\mathrm{BMI}\left(\mathrm{Kg} / \mathrm{m}^{2}\right)$ mean $\pm \mathrm{SD}$ & $43.9 \pm 6.7$ & $38.5 \pm 5.02$ & 0.0001 \\
\hline Weight $(\mathrm{kg})$ mean $\pm \mathrm{SD}$ & $123.1 \pm 19.4$ & $105.3 \pm 19.1$ & 0.0001 \\
\hline $\mathrm{EBW}(\mathrm{Kg})$, mean $\pm \mathrm{SD}$ & $52.8 \pm 18.1$ & $37.3 \pm 15.7$ & 0.0001 \\
\hline $\begin{array}{l}\text { Comorbidities } \\
\text { Hypertension, n (\%) } \\
\text { Diabetes, n (\%) } \\
\text { Dyslipidemia, n (\%) } \\
\text { OSAS, n (\%) }\end{array}$ & $\begin{array}{l}28(56 \%) \\
10(20 \%) \\
12(24 \%) \\
14(28 \%)\end{array}$ & $\begin{array}{c}17(34 \%) \\
6(12 \%) \\
11(22 \%) \\
9(18 \%)\end{array}$ & $\begin{array}{l}>0.5 \\
>0.5 \\
>0.5 \\
>0.5\end{array}$ \\
\hline $\begin{array}{c}\text { ASA, n (\%) } \\
\text { I } \\
\text { III }\end{array}$ & $\begin{array}{cc}1 & (2 \%) \\
38 & (76 \%) \\
11 & (22 \%)\end{array}$ & $\begin{array}{c}2(4 \%) \\
40(80 \%) \\
8(16 \%)\end{array}$ & $>0.5$ \\
\hline Operative time (min) & $86(40-131)$ & $90(65-145)$ & $>0.5$ \\
\hline $\begin{array}{l}\text { Concurrent surgeries, n (\%) } \\
\text { Cholecystectomy } \\
\text { HH repair } \\
\text { Adhesiolysis } \\
\text { Band removal }\end{array}$ & $\begin{array}{c}4(8 \%) \\
5(10 \%) \\
4(8 \%) \\
1(2 \%)\end{array}$ & $\begin{array}{c}2(4 \%) \\
3(6 \%) \\
3(6 \%) \\
0\end{array}$ & $>0.5$ \\
\hline Hospital stay(days), median (range) & $3.5(2-21)$ & $5.1(3-31)$ & $>0.5$ \\
\hline
\end{tabular}


the LSG group, requiring laparoscopic hemostasis. In this group, a leak also occurred on the fifth day after surgery. Furthermore, a reintervention was needed when a drainage and feeding jejunostomy was performed. This patient required 21 days of hospitalization and the fistula was finally closed through an endoscopic approach (over-the-scope clip). In the LGP group, we also encountered one leak on postoperative day 2 ; the patient needed an open reintervention with the close of the fistula. This patient required 31 days of hospitalization with 7 days in intensive care unit. Two patients from LGP group had an acute gastric outlet obstruction (within the postoperative week), where the second row of the plication had to be partially undone at its pyloric end through laparoscopic approach. There were more minor complications in this group like nausea and vomiting, observed in 12 cases (24\%), requiring prolonged gastric aspiration and conservative treatment.

The overall complication rate accounted for $40 \%$ of the LGP group and $12 \%$ of the LSG group, the differences being statistically significant $(p<0.001)$. However, if only major complications (Clavien-Dindo class III and IV) are considered (e.g., hemorrhage, leaks/ abscess and gastric outlet syndrome), no statistically significant differences can be seen between the study groups. All postoperative complications are included in Table 2.

There were also some patients who needed reoperation at more than 30 days after the initial intervention. In the LGP group, two cases with persistent nausea needed removal of two stitches from the second row of plication, performed through laparoscopy two and four months after LGP, respectively. Two other cases had an undiagnosed, preoperative hiatal hernia and these patients developed progressive dysphagia due to the prolapse of the gastric fold through the cardia. Revision surgery was performed, involving taking down the plication of the fundus, followed by Toupet fundoplication, with the rest of the stomach remaining plicated. Three patients with unsatisfactory weight loss or weight regain one year after LGP underwent a LSG procedure during follow-up. In the LSG group, there were two cases of progressive weight regain, for whom re-sleeve and banded sleeve procedures were performed at 25 and 29 months from the initial surgery, respectively. This group also included one

Table 2. Table 2. Postoperative complications and redo surgery in the study groups

\begin{tabular}{|c|c|c|c|}
\hline Characteristics & LSG (50 pts) & LGP (50 pts) & $P$ value \\
\hline Age(years) mean $\pm S D$ & $40.4 \pm 9.7$ & $38.2 \pm 10.2$ & $>0.5$ \\
\hline Complications & LGP (50 patients); n (\%) & LSG (50 patients); $n$ (\%) & $P$ value \\
\hline Bleeding (requiring reintervention) & $1(2 \%)$ & $2(4 \%)$ & $>0.5$ \\
\hline Leaks & $1(2 \%)$ & $1(2 \%)$ & $>0.5$ \\
\hline Gastric outlet obstruction (acute) & $2(4 \%)$ & 0 & $>0.5$ \\
\hline Abscess & $1(2 \%)$ & $1(2 \%)$ & $>0.5$ \\
\hline Minor (nausea/vomiting) & $12(24 \%)$ & 0 & 0.001 \\
\hline Wound infection & $1(2 \%)$ & $1(2 \%)$ & $>0.5$ \\
\hline Port-site hernia & $2(4 \%)$ & $1(2 \%)$ & $>0.5$ \\
\hline Clavien-Dindo I-II & $15(30 \%)$ & $2(4 \%)$ & 0.0001 \\
\hline Clavien-Dindo III-IV & $5(10 \%)$ & $4(8 \%)$ & $>0.5$ \\
\hline GERD, HH symptoms/reinterventions & $4 / 2(8 / 4 \%)$ & $4 / 1(8 / 2 \%)$ & $>0.5$ \\
\hline Gastric prolapse (chronic) & $2(4 \%)$ & 0 & $>0.5$ \\
\hline Reoperations & $12(24 \%)$ & $7(14 \%)$ & $>0.5$ \\
\hline Before 30 days & 5 & 4 & $>0.28$ \\
\hline After 30 days & 7 & 3 & 0.47 \\
\hline Readmissions & $11(22 \%)$ & $3(6 \%)$ & 0.04 \\
\hline Mortality & 0 & 0 & $>0.5$ \\
\hline
\end{tabular}


patient with severe de novo reflux who underwent a posterior cruroplasty nine months after the LSG.

The patients were followed for three years postoperatively, the median follow-up being 3.2 years; Table 3 includes mean \%TWL, $\triangle \mathrm{BMI}$, and $\% \mathrm{EWL}$ values in the follow-up period for the two groups studied.

Our statistical analysis showed significant differences between the two groups in terms of weight reduction. Starting from 6 months after surgery, weight reduction was statistically significant in favor of the LSG group, with the highest differences evident between two and three years after the operation $(p=0.0001)$. When analyzing weight loss only in LGP group we noticed significant differences. We observed that patients with an initial lower weight and BMI (under $40 \mathrm{~kg} / \mathrm{m}^{2}$ ) presented a significantly better weight loss at 1.5 years after surgery and further on $(p<0.001)$ as compared with the sub-group of LGP patients with initial BMI over $40 \mathrm{~kg} / \mathrm{m}^{2}$.

In terms of resolution (meaning no medication), or significant improvement (meaning reduction of medication) of the main comorbidities, the results of both interventions are presented in Table 4. No differences were found between the two procedures in this regard.

\section{Discussion}

Obesity is widely accepted as an epidemic and currently it has a substantial impact on public health. According to recent data, almost 20\% of the population in Romania is obese and socio-economic developments in recent years make grim predictions for the forthcoming decades (8). Although efforts are being made to prevent and combat obesity through campaigns that promote hypocaloric diets and physical activity, our country currently has no

Table 3. Weight-loss effect. Data were expressed by mean $\pm S D$. Student unpaired test. LGP= laparoscopic gastric plication; LSG= laparoscopic sleeve gastrectomy; \%EBW=percent excess body weight; $\Delta \mathrm{BMI}=$ change in body mass index $\left(\mathrm{kg} / \mathrm{m}^{2}\right), \% \mathrm{TWL}=$ (total weight loss), $\Delta \mathrm{BMI}=$ change in $\mathrm{BMI}$

\begin{tabular}{|c|c|c|c|c|c|}
\hline \multicolumn{2}{|l|}{ Number of values } & Number of patients & \multirow{2}{*}{$\begin{array}{l}\text { Mean } \\
51.07\end{array}$} & \multirow{2}{*}{$\begin{array}{c}\text { Std Deviation } \\
17.2\end{array}$} & \multirow{2}{*}{$\frac{\text { P Value }}{0.09}$} \\
\hline 6 months \%EBW & LGP & 50 & & & \\
\hline & LSG & 47 & 58.1 & 23 & \\
\hline \multirow[t]{2}{*}{6 months $\Delta \mathrm{BMI}$} & LGP & 50 & 8.34 & 2.05 & 0.001 \\
\hline & LSG & 47 & 11.45 & 2.83 & \\
\hline \multirow[t]{2}{*}{6 months \%TWL } & LGP & 50 & 21.61 & 4.11 & 0.0001 \\
\hline & LSG & 47 & 26.04 & 5.38 & \\
\hline \multirow[t]{2}{*}{12 months \%EBW } & LGP & 44 & 61.4 & 16.8 & 0.006 \\
\hline & LSG & 41 & 71.9 & 17.9 & \\
\hline \multirow[t]{2}{*}{12 months $\Delta \mathrm{BMI}$} & LGP & 44 & 10.95 & 3.02 & 0.01 \\
\hline & LSG & 41 & 15.54 & 3.84 & \\
\hline \multirow[t]{2}{*}{12 months \%TWL } & LGP & 44 & 28.22 & 4.98 & 0.0001 \\
\hline & LSG & 41 & 34.67 & 5.69 & \\
\hline \multirow[t]{2}{*}{24 months \%EBW } & LGP & 16 & 64.9 & 20 & 0.0001 \\
\hline & LSG & 30 & 75 & 16.8 & \\
\hline \multirow[t]{2}{*}{24 months $\Delta \mathrm{BMI}$} & LGP & 16 & 9.36 & 2.55 & 0.001 \\
\hline & LSG & 30 & 16.86 & 5.7 & \\
\hline \multirow[t]{2}{*}{24 months \%TWL } & LGP & 16 & 23.28 & 5.78 & 0.0001 \\
\hline & LSG & 30 & 37.15 & 7.79 & \\
\hline \multirow[t]{2}{*}{36 months \%EBW } & LGP & 6 & 53.8 & 18.5 & 0.008 \\
\hline & LSG & 16 & 67.2 & 20.1 & \\
\hline \multirow[t]{2}{*}{36 months $\Delta \mathrm{BMI}$} & LGP & 6 & 8.95 & 3.89 & 0.001 \\
\hline & LSG & 16 & 17.2 & 5.96 & \\
\hline \multirow[t]{2}{*}{36 months \%TWL } & LGP & 6 & 21.08 & 10.22 & 0.0006 \\
\hline & LSG & 16 & 36.97 & 7.27 & \\
\hline
\end{tabular}


Table 4. Evolution of comorbidities after two types of surgeries. LGP = laparoscopic gastric plication; $\mathrm{LSG}=$ laparoscopic sleeve gastrectomy.

\begin{tabular}{lccc}
\hline & $\begin{array}{c}\text { Resolution/Improvement } \\
\text { after LGP, } \mathbf{n}(\%)\end{array}$ & Resolution/improvement after LSG, $\mathbf{n}$ (\%) & p-value \\
\hline Hypertension & $8(47 \%)$ & $17(60.7 \%)$ & 0.02 \\
\hline Diabetes & $4(66.6)$ & $7(70 \%)$ & $>0.5$ \\
\hline OSAS & $7(77.7)$ & $11(78.5 \%)$ & $>0.5$ \\
\hline Dyslipidemia & $5(45.4)$ & $6(50 \%)$ & $>0.5$ \\
\hline
\end{tabular}

national program dedicated to the treatment of obesity. However, in the last 20 years, a number of university surgical centers in Romania have introduced and developed various bariatric techniques, with a tendency for LSG to become the preferred one $(6,7)$. Various arguments, including economic ones, have enabled some of our patients to benefit from another type of restrictive bariatric intervention, namely LGP (9). This rather new, emerging procedure was originally described by Talebpour and Amoli (10). It is important to be mentioned that this operation is still considered by many authors as being in the investigative stage (9). This is not surprising at all, most LGP studies come from countries where public health systems do not fully cover the costs of more expensive bariatric surgery (e.g., LSG and LGB) (11-13). The present comparative, case-control study attempts to help responding to a pending question in the literature concerning this recently introduced restrictive technique: is LGP an effective technique in the treatment of obesity and which niche of patients best fits this surgery?

The recent literature includes several studies that analyze short- and medium-term outcomes after LGP. However, the conclusions are contradictory and justify the maintenance of this surgery under investigation $(11,14)$. Furthermore, there are few comparative studies of LGP and LSG procedures with a follow-up longer than three years (12-16). The present study examines two important groups of patients who underwent either LSG or LGP surgery in a single center and were followed for up to three years. In an effort to minimize selection bias, we included patients operated on in the same period by the two surgeons who perform most of the bariatric surgeries in our service, one almost exclusively performing LSG and the other being proficient in LGP. Both groups were similar in demographic respects, but there were notable differences in anthropomorphic characteristics. We included in our study 50 consecutive LGP patients who were matched with 50 LSG - cases operated on during the same time period; the two groups were similarly as regards demographic criteria but there were significant anthropomorphic differences, patients with a low initial BMI being considered more suitable for LGP.

The LGP procedure has emerged as an alternative to the LSG, achieving restriction by gastric imbrication through sero-muscular stitches, thus avoiding stapling and its potential risks, i.e., hemorrhage and gastric fistula in particular. However, there are studies that contradict this claim. For example, in a study by Albanese et al. (17) involving 56 obese patients (with an initial mean BMI of 40.31) who underwent LGP, the reported results showed a general complication rate of over $30 \%$, with surgery revision required in 30 patients, primarily due to gastric prolapse and insufficient weight loss. In contrast, a recent meta-analysis by Perivolitis et al. (18) did not find any differences between LSG surgery and LGP concerning major complications, but emphasized the fact that the LSG is a much safer operation when compared to LGP. Similarly, our study found no differences between groups as regards major complications (Clavien-Dindo class III-IV), but an early leak was reported in LGP group along with two reinterventions done for acute gastric outlet syndrome. 
We reported here an increased rate of minor complications after LGP in the early postoperative days, especially nausea, vomiting or sialorrhea, which required prolonged gastric aspiration, hospitalization or even readmissions.

Another issue concerns the revision rate after these procedures. In the available literature, LSG is generally recognized as being a safe procedure with a low revision rate $(3,12,16)$. Data relating to the LGP revision rate is contradictory. The majority of authors describe no difference between the two techniques in this regard $(9,11)$. However, some studies report high reintervention rates after LGP due to late complications or inadequate weight loss $(17,19)$. With seven reinterventions performed in the LGP group 30 days after the primary one, our revision rate is much lower. In a previous collective work (20), we showed that the real problem of LGP is that the surgeon cannot assess the residual gastric volume and we described a new LGP technique by using real-time imaging of the stomach pouch.

As before mentioned, the conclusions of comparative studies regarding the weight loss following LSG and LGP are not conclusive $(21,22)$. However, many authors have shown the superiority of LSG in this regard (11-13, 23) and our mid-term analysis is in concordance with these studies, showing statistical differences between groups in terms of all checked weight loss variables at each timepoint during follow-up. However, the higher rates of weight loss reported in our study in the LGP group at least in short-term, should be interpreted in relation to the lower baseline BMI (compared to the LSG group). Furthermore, we noted better results in term of weight loss 1 year after LGP in the group of patients with an initial lower BMI (under 40 $\mathrm{Kg} / \mathrm{m}^{2}$ ) when compared with patients with an initial higher BMI. Once again these results are similar to short and medium-term results after LGP that have been reported by other authors. For example, Skrekas et al. (24) noted that \%EWL was significantly higher in patients with a BMI <45. Furthermore, a study of 624 cases by Rodriquez et al. (25) showed higher rates of weight loss in the group of patients with an initial BMI below 40 . In addition, our statistical analysis did not find any differences in improved comorbidity rates between the two procedures, and these results are, again, similar to most of the published comparative analyses $(12,13,15,18)$.

One aspect which is commonly considered to be superior in the LGP procedure is its potential reversibility $(9,13,15,18)$. In the present work we also noticed this advantage during reinterventions performed in the first few months after the primary surgery, where the plication was simply restored by cutting the stitches. However, the subsequent fibrosis process is often so important that it makes the task of undoing the plication difficult and even dangerous, aspect noted by us during reintervention after six months.

We did not analyze the comparative costs. However, it is well known that in Romania the average cost of LSG surgery is much higher than LGP. Data regarding the costs are unofficial and generally provided by private medical centers, but they correspond to already published results (26). Therefore, the financial variable favors LGP in this regard as a significantly cheaper intervention compared to other bariatric operations, including LSG.

Our study has certain limitations. Firstly, it is a retrospective, small sample size, nonrandomized and un blinded study, with heterogeneity between the two groups in terms of the anthropomorphic criteria, which undoubtedly introduces a certain degree of bias. Even though the two techniques were performed by surgeons with comparable experience (each with more than 150 cases performed before starting the study) there were technical variants in each procedure that may be responsible for the introduction of bias. Also, a major limitation is referring to the fact that LSG cohort is significantly different from LGP one, with our future efforts focusing on the medium-long term durability of LGP, as well as the fact that our study is currently lacking a cost-effectiveness comparison of both methods used. 


\section{Conclusions}

The results of the present study show that LGP is an LSG-like technique in terms of the length of hospitalization and improvement of the main comorbidities. However, the LSG procedure is superior in terms of medium- to long-term weight reduction and overall complication rate. In certain cases, LGP is a potentially reversible operation, at least when the redo surgery is performed in the early postoperative period. LGP is a technique with good results especially in the patients with a lower BMI (less than $40 \mathrm{~kg} / \mathrm{m}^{2}$ ). Further prospective randomized trials and metaanalyses are required to validate our results.

\section{Acknowledgments}

This paper was done under the frame of project no. 6869/12.06.2014, University of Medicine and Pharmacy Tîrgu Mureş.

\section{Conflicts of Interest}

All authors declare no conflict of interest.

\section{References}

1. Obesity and overweight. Fact Sheet no 311 . World Health Organization (WHO). Revised May 2014

2. Kelly T, Yang W, Chen CS, Reynolds K, He J. Global burden of obesity in 2005 and projections to 2030. Int J Obes. 2008; 32(9):1431-7.

3. Rosenthal RJ, Diaz AA, Arvidsson D, Baker RS, Basso N, Bellanger D, et al. International Sleeve Gastrectomy Expert Panel Consensus Statement: best practice guidelines based on experience of 12,000 cases. Surg Obes Relat Dis. 2012;8:8-19.

4. Bužga M, Švagera Z, Tomášková H, Hauptman K, Holéczy P. Metabolic effects of sleeve gastrectomy and laparoscopic greater curvature plication: an 18-month prospective, observational, open-label study. Obes Surg. 2017;27:3258-3266.

5. NIH conference. Gastrointestinal surgerz for severe obesitz. Consensus development conference panel. Ann Intern Med 1991; 115(12):956-961.

6. Neagoe RM, Mureșan M, Bancu Ș, Balmos I, Băișan V, Voidăzan S, et al. Results of laparoscopic sleeve gastrectomy - 5-Year Follow-up study in an Eastern European Emerging Bariatric Center. Obes Surg. 2017:4:983-989.

7. Neagoe RM, Muresan M, Timofte D, Darie R, Razvan I, Voidazan S, et al. Long-term outcomes of laparoscopic sleeve gastrectomy - a singlecenter prospective observational study. Videosurgery Miniinv 2019; 14(2):242-248.
8. WHO Global Health Observatory Data Repository (online database). Geneva, World Health Organization. 2013 (http://apps.who.int/gho/ data/view.main, accessed 21 May 2013)

9. ASMBS policy statement on gastric plication. Surg Obes relat Dis 2011;7:262

10. Talebpour M, Amoli BS. Laparoscopic total gastric vertical plication in morbid obesity. J Laparoendosc Adv Surg Techn. 2007;17:793-798.

11. Abdelbaki TN, Sharaan M, Abdel-Baki NA, Katri K. Laparoscopic gastric greater curvature plication versus laparoscopic sleeve gastrectomy: early outcome in 140 patients. Surg Obes Rel Dis. 2014;10: 1141-1146.

12. Toprak SS, Gultekin Y, Okus A. Comparison of laparoscopic sleeve gastrectomy and laparoscopic gastric plication: one year follow-up results. Turkish J Surg. 2016;32:18-22.

13. Abouzeid MM, Taha 0 . Laparoscopic sleeve gastrectomy versus laparoscopic gastric greater curvature plication: a prospective randomized comparative study. Egyptian J Surg. 2015;34:41.

14. Chouillard E, Schoucair N, Alsabah S, Alkandari B, Montana L, Dejonghe $B$, et al. Laparoscopic gastric plication (LGP) as an alternative to laparoscopic gastric sleeve (LSG) in patients with morbid obesity: a preliminary, short-term, case-control study. Obes Surg. 2016;26:1167-1172.

15. Verdi D, Prevedello L, Albanese A, Lobba A, Foletto M. Laparoscopic gastric plication (LGCP) vs sleeve gastrectomy (LSG): a single institution experience. Obes Surg. 2015;25;1653-1637.

16. Grubnik VV, Ospanov OB, Namaeva KA, Medvedev OV, Kresyun MS. Randomized control trial comparing laparoscopic greater curvature plication versus laparoscopic sleeve gastrectomy. Surg endosc. 2016;30:2186-2191.

17. Albanese A, Prevedello L, Verdi D, Nitti D, Vettor R, Foletto $M$. Laparoscopic gastric plication: an emerging bariatric procedure with high surgical revision rate. Bariatric Surg Pract Patient Care. 2015;10.93-8

18. Perivoliotis K, Sioka E, Katsogridaki G, Zacharoulis D. Laparoscopic gastric plication versus laparoscopic sleeve gastrectomy: an up-todate systematic review and meta-analysis. J Obes. 2018:1:1-14.

19. Ji Y, Wang Y, Zhu J, Shen D. A systematic review of gastric plication for the treatment of obesity. Sug Obes Relat Dis. 2014;10: 1226-1232.

20. Borz C, Bara TJ, Bara T, Suciu A, Denes M, Borz B, et al. Laparoscopic gastric plication for the treatment of morbid obesity by using real-time imaging of the stomach pouch. Ann Ital Chir. 2017;88:392-8.

21. Park YH, Kim SM. Short-term outcomes of laparoscopic greater curvature plication and laparoscopic sleeve gastrectomy in patients with a body mass index of 30 to $35 \mathrm{~kg} / \mathrm{m}^{2}$. Yonsei Med J. 2017:58: 1025-1030

22. Talebpour M, Sadid D, Talebpour, A.; Sharifi, A.; Davari, F.V. Comparison of short-term effectiveness and postoperative complications: laparoscopic gastric plication vs laparoscopic gastric sleeve. Obes Surg. 2017;28:996-1001.

23. Shen D, Ye H, Wang Y, Ji Y, Zhan X, Zhu J, et al. Comparation of shortterm outcomes between laparoscopic greater curvature plication and laparoscopic sleeve gastrectomy. Surg Endosc. 2013; 27:2768-2774.

24. Skrekas G, Antiochos K, Stafyla VK. Laparoscopic greater curvature plication: results and complications in a series of 135 patients. Obes Surg. 2011;21.1657-1663.

25. Rodríguez G, Martínez A, Viramontes-So M, Sanmiguel L, Jiménez JA, Limon J, et al. New bariatric procedure: the stomach sparing gastric sleeve. Surg Technol Int. 2015, 27, 116-122.

26. Chouillard E, Schoucair N, Alsabah S, Alkandari B, Montana L, Dejonghe B, et al. Laparoscopic gastric plication (LGP) as an alternative to laparoscopic gastric sleeve (LGS) in patients with morbid obesity: a preliminary, short term, case-control study. Obes Surg. 2016;26:1167-1172. 